\title{
Giant prostatic hyperplasia: report of a previously asymptomatic man presenting with gross hematuria and hypovolemic shock
}

Hiperplasia prostática gigante: hematúria macroscópica com choque hipovolêmico em paciente previamente assintomático

\author{
Marcelo Langer Wroclawski ${ }^{1,2}$, Ariê Carneiro ${ }^{1,2}$, Rodrigo Alves Tristão ${ }^{2}$, Paulo Kouiti Sakuramoto², \\ Jorg Daoud Merched Youssef², Antonio Correa Lopes Neto $^{2}$, Lucila Heloísa Simardi Santiago², \\ Antonio Carlos Lima Pompeo ${ }^{2}$
}

\begin{abstract}
Giant prostatic hyperplasia is a rare condition characterized by very high volume benign prostatic enlargement $(>500 \mathrm{~g})$. Few cases have been reported so far and most of them are associated with severe lower urinary symptoms. We report the first case of asymptomatic giant prostatic hyperplasia in an elderly man who had a $720 \mathrm{~g}$ prostate adenoma, sudden gross hematuria and hypovolemic shock. The patient was successfully treated with open transvesical prostatectomy and had an uneventful postoperative recovery.
\end{abstract}

Keywords: Prostatic hyperplasia; Prostatectomy; Hematuria; Hemorrhage; Shock, Lower urinary tract symptoms

\section{RESUMO}

A hiperplasia prostática gigante é uma condição rara caracterizada por aumento benigno prostático significativo, com volume maior que $500 \mathrm{~g}$. Existem poucos casos relatados e, em sua maioria deles está associada a sintomas graves do trato urinário inferior. Relatamos aqui o primeiro caso de hiperplasia prostática benigna assintomática em paciente idoso com próstata de $720 \mathrm{~g}$, hematúria macroscópica de início súbito e choque hipovolêmico. 0 paciente foi submetido com sucesso à prostatectomia suprapúbica, sem intercorrências no intra e pós-operatório.

Descritores: Hiperplasia prostática; Prostatectomia; Hematúria; Hemorragia; Choque; Sintomas do trato urinário inferior

\section{INTRODUCTION}

Benign prostatic hyperplasia (BPH) is a common condition that affects many aging men and it may be associated with significant quality of life issues.

"Giant prostatic hyperplasia" (GPH) is a term that describes rare cases of extremely enlarged prostate glands, weighing greater than 500g. ${ }^{(1)}$ Typically, patients with GPH have severe symptoms and seek medical care to treat their voiding complaints.

We report the first case, to our knowledge, of a man with GPH and without voiding symptoms, who presented sudden gross hematuria and hypovolemic shock.

\section{CASE REPORT}

An afro-descendent, 82-year-old man was admitted to the emergency room with painless macroscopic hematuria for 5 days without clots.

The patient denied any prior episodes of hematuria and did not complain of voiding symptoms. There was no history of smoking, alcohol abuse, severe comorbidities (the patient was treated with angiotensin-converting enzyme inhibitor to control mild arterial hypertension), or use of anti-coagulants or blood thinners.

\footnotetext{
Hospital Israelita Albert Einstein, São Paulo, SP, Brazil.

2 Faculdade de Medicina do ABC, Santo André, SP, Brazil.

Corresponding author: Marcelo Langer Wroclawski - Rua Iguatemi, 192, room 43 - Itaim-Bibi - Zip code: 01451-010 - São Paulo, SP, Brazil - Phone: (55 11) $3168-2130$ - E-mail: mwroclawski@terra.com.br Received on: July 7, 2013 - Accepted on: Apr 23, 2014

DOI: 10.1590/S1679-45082015RC2905
} 
On physical examination the patient was dehydrated and with pale mucosa. Upon admission his heart rate was $112 \mathrm{bpm}$ and blood pressure was $90 / 70 \mathrm{mmHg}$. Abdominal palpation did not reveal any evident masses. The digital rectal examination revealed a large prostate with an estimated volume significantly greater than $100 \mathrm{~g}$, but with benign consistency and without nodules.

The individual underwent prompt bladder catheterization (with large catheter) and vesical irrigation with saline solution.

He also had acute renal insufficiency, with creatinine and urea levels of $1.9 \mathrm{mg} / \mathrm{dL}$ and $64.0 \mathrm{mg} / \mathrm{dL}$, respectively. The patient underwent immediate volume resuscitation with saline and blood transfusion.

An abdominal ultrasound was performed when the patient was hospitalized in the emergency room, which demonstrated moderate bilateral hydronephrosis and a pelvic mass measuring $15 \times 16 \times 16 \mathrm{~cm}$. The computerized tomography (CT) scan had confirmed the evidence of urinary obstruction and a large pelvic mass representing the prostate (Figure 1).
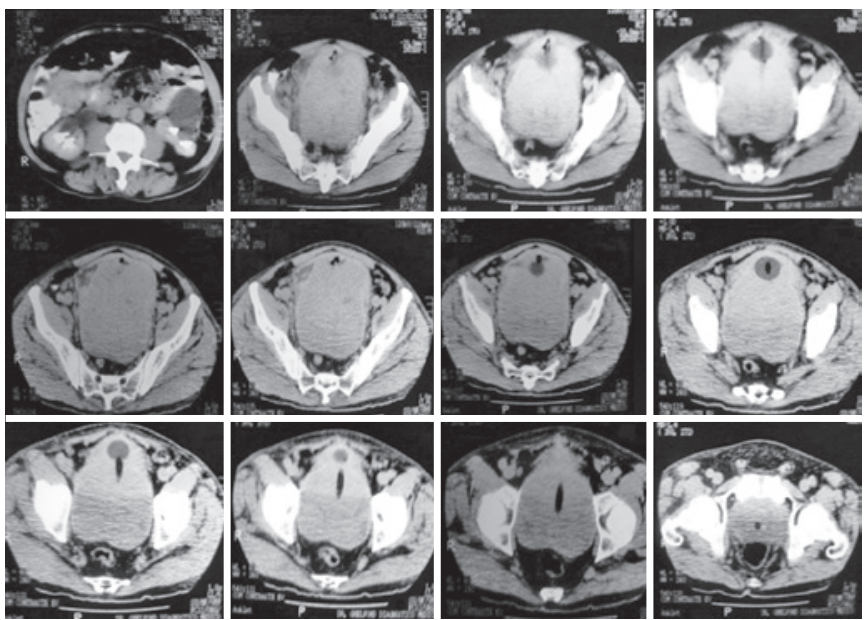

Figure 1. Computerized tomography scan showing urinary obstruction (hydronephrosis) and a large pelvic mass representing the prostate

Prostatic specific antigen (PSA) levels measured after lower urinary tract manipulation were as high as $122.0 \mathrm{ng} / \mathrm{mL}$. Therefore, prostate trans-rectal ultrasound guided biopsies were performed to assess the possibility of a prostate adenocarcinoma or sarcoma. No evidence of malignancy was identified in the biopsy specimens.

Subsequently, the patient underwent an uneventful open trans-vesical prostatectomy (TVP). The procedure time was about 100 minutes and the no further blood transfusions were required. The prostatic adenoma, extirpated as a single piece, measured $17 \times 16 \times 13.5 \mathrm{~cm}$ and weighed $720 \mathrm{~g}$ (Figure 2).
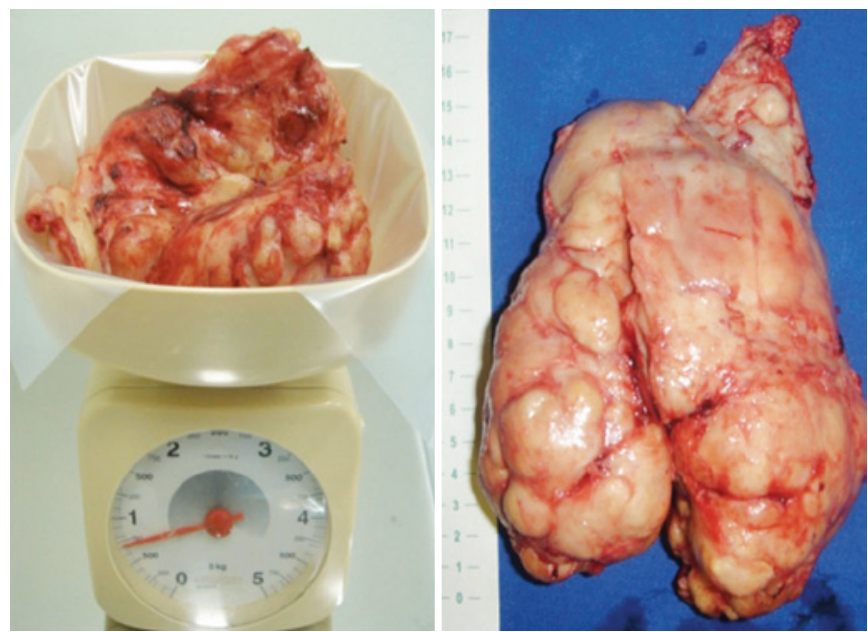

Figure 2. The prostatic adenoma, extirpated as a single piece, measuring $17.0 \times 16.0 \times 13.5 \mathrm{~cm}$ and weighing $720 \mathrm{~g}$

Final pathological analysis revealed a whitish, firm and multinodular surface with cysts and diffuse hemorrhagic areas compatible with prostatic nodular hyperplasia with multiple anemic infarction foci and glandular squamous metaplasia.

At 1 year of follow-up, the patient returned to clinic with normal renal function, satisfactory urinary flow, and complete continence, although currently he is on treatment with anti-muscarinic medications due to urinary urgency.

\section{DISCUSSION}

The term "giant prostatic hyperplasia" was defined by Fishman and Merrill as glands exceeding 500g.(1) In our case, the preoperative CT showed a large pelvic mass representing the prostate and, after surgery, the specimen weight was $720 \mathrm{~g}$.

It is well-known that anatomic measurements of the prostate do not adequately distinguish patients who seek medical care from those who do not. ${ }^{(2)}$ Prostatic volume measured either by trans-rectal ultrasound or magnetic resonance imaging is poorly correlated with frequency, quality of life, urinary flow rate, residual urine, and pressure-flow parameters. However, it is unexpected for a man with such a large gland to remain asymptomatic prior to admission to the emergency room with hematuria and class III hemorrhagic, and hypovolemic shock, which require urgent blood transfusion.

Gross hematuria is an uncommon complaint in men with enlarged prostate, which is rarely seen as an initial presentation. Prior series report an prevalence rate of approximately $2.5 \%$ of macroscopic hematuria in men with BPH. ${ }^{(3)}$ 
The exact etiology of bleeding in men with enlarged prostate is unclear but may be attributable to increased microvessel density level ${ }^{(4)}$ and vascular endothelial growth factors over-expression. ${ }^{(5)}$ In addition, in these patients hypertension has been associated as a risk factor for hematuria. ${ }^{(6)}$

Biopsies to ensure malignancy status prior to initiate definitive treatment are of utmost importance given its potential impact on therapeutic choice. Prostate adenocarcinoma was one of the main concern in our patient given his age and elevated PSA (over $100 \mathrm{ng} / \mathrm{mL}$ ). Because of the size of the prostate, the sarcoma was another possibility that needed to be excluded, ${ }^{(7)}$ although such affection rarely induces PSA elevation.

Upper urinary tract deterioration and gross hematuria leading to hypovolemic shock are well-known indications for BPH surgical treatment. Although minimally invasive approaches such as robot-assisted simple prostatectomy ${ }^{(8)}$ can be used for the treatment of BPH, the open surgery remains the gold standard procedure for benign, large volume, prostatic hyperplasia. ${ }^{(9)}$

Sutherland et al. reported unsuccessful robot-assisted simple prostatectomy for a man with severe prostatomegaly $(260 \mathrm{~g}) .{ }^{(10)}$ Hence, the analysis of a contemporary series of patients revealed that trans-vesical prostatectomy is associated with significant improvement in symptom score scales, post-void residual urine volume, and maximal flow rate, along with a low incidence of long-term complications and need of re-operation as well as a durable therapeutic effect. $^{(11)}$

Similar to others, ${ }^{(12)}$ we consider simple prostatectomy as the primary recommended treatment option for GPH. For this reason, a suprapubic open trans-vesical prostatectomy was performed. Operation time was short and no major complications occurred.

GPH is an extremely rare condition. A MEDLINE/ PubMed search revealed no more than 20 reports of prostates weighing greater than 500.(13,14) The above reported case is among the five greatest prostate glands ever described, ${ }^{(14)}$ and it is the first one with such unusual presentation, characterized by a complete absence of voiding symptoms followed by sudden gross hematuria that resulted in hypovolemic shock.

\section{REFERENCES}

1. Fishman JR, Merrill DC. A case of giant prostatic hyperplasia. Urology. 1993;42(3):336-7. Review.

2. Jacobsen SJ, Girman CJ, Guess HA, Panser LA, Chute CG, Oesterling JE, et al Do prostate size and urinary flow rates predict health care-seeking behavior for urinary symptoms in men? Urology. 1995;45(1):64-9.

3. Hunter DJ, Berra-Unamuno A, Martin-Gordo A. Prevalence of urinary symptoms and other urological conditions in Spanish men 50 years old or older. J Urol. 1996;155(6):1965-70.

4. Foley SJ, Bailey DM. Microvessel density in prostatic hyperplasia. BJU international. 2000;85(1):70-3.

5. Häggström S, Tørring N, Møller K, Jensen E, Lund L, Nielsen JE, et al. Effects of finasteride on vascular endothelial growth factor. Scand J Urol Nephrol. 2002;36(3):182-7.

6. Guo LJ, Tang Y, Guo CM, Zhang XH. Impact of primary hypertension on hematuria of the patients with benign prostatic hyperplasia. Chin Med J (Engl). 2010;5;123(9):1154-7.

7. Varghese SL, Grossfeld GD. The prostatic gland: malignancies other than adenocarcinomas. Radiol Clinics North Am. 2000;38(1):179-202. Review.

8. Vora A, Mittal S, Hwang J, Bandi G. Robot-assisted simple prostatectomy: multi-institutional outcomes for glands larger than 100 grams. J Endourol. 2012;26(5):499-502.

9. Rigatti P, Cestari A, Gilling P. The motion: large BPH should be treated by open surgery. Eur Urol. 2007;51 (3):845-7; discussion 847-8.

10. Sutherland DE, Perez DS, Weeks DC. Robot-assisted simple prostatectomy for severe benign prostatic hyperplasia. J Endourol. 2011;25(4):641-4.

11. Varkarakis I, Kyriakakis Z, Delis A, Protogerou V, Deliveliotis C. Long-term results of open transvesical prostatectomy from a contemporary series of patients. Urology. 2004;64(2):306-10. Review.

12. Ogawa S, Manome M, Yabe M, Kuma $Y$, Yamaoka M, Sato $Y$, et al. A giant prostatic hyperplasia treated by open surgery. Int J Gen Med. 2012;5:1009-12.

13. Akpo $E$, Akpo M. Giant benign prostatic hyperplasia in a nigerian: report of a case. The Internet Journal of Urology. 2010;8(1).

14. Üçer 0 , Baser 0 , Gümüs B. Giant prostatic hyperplasia: Case report and literature review. Dicle Medical Journal. 2011;38(4):489-91. 